\title{
Process-oriented approach to competency management using ontologies
}

\author{
Ilona Pawełoszek \\ Częstochowa University of Technology, \\ Faculty of Management \\ al. Armii Krajowej 19 B, 42-201 Częstochowa, \\ Poland \\ ipaweloszek@zim.pcz.pl
}

\begin{abstract}
Popularization of process approach as a standard necessitates changing the ways of defining and identifying requisite competencies. They should be seen in the framework of tasks implemented within the business process. The complex nature of competencies requires expressive forms of description regarding their multidimensional character therefore codification of competencies is the area predestinated to make use of ontologies. The aim of this paper is to show how the ontology describing competencies can be linked with business process models to support process-oriented, dynamic competency management in a company. With this aim in mind a proposal of practical implementation of ontology-enhanced business process model was presented and illustrated by the example of software development.
\end{abstract}

\section{INTRODUCTION}

$\mathrm{D}$ YNAMIC economic environment along with new challenges posed by globalization and latest information technology developments are reflected in a steady growth of interest in competency management. The complex nature of competencies requires expressive forms of description regarding their multidimensional character. According to Bratnicki [1 p.64], competencies are „complex bundle of resources, processes and abilities" which are important for gaining competitive advantage on a particular market. The competencies of organization allow for conducting its business by coordinating its owned resources. In the light of resource-based view, competitive advantage is based on a concept of distinctive competencies of organization. This term was introduced by Philip Selznick in 1957 referring to the activities which organization does particularly well comparing to its competitors [2]. Similar concept of core competencies was put forward in 1990 by Prahalad and Hamel [3] as the bedrock upon which to build strategies.

From this point of view, apart from identification and evaluation of distinctive competencies, it is also important to monitor changes in the environment regarding new needs, products and technologies. These changes create the need for adjustment of business processes and searching or developing new competencies. Human capital is the carrier of the organization's knowledge and skills, therefore developing core competencies requires developing individual and team competencies.
The vision of the strategic core competencies is the driver for development of collective or individual competencies. The requirements in this area should follow from the processes and tasks performed by the working group or the whole organization. Therefore the main focus of this study is on individual and team competencies.

Popularization of both process and ontological approach as standards necessitates changing the ways of defining and identifying requisite competencies. They should be seen in the framework of tasks implemented within the process rather than by position of the employee in organization hierarchy. Therefore, in dynamic environment of contemporary organizations a Competency-oriented Business Process Analysis [4] can be the right choice. A Business Process Model is a step-by-step description of what one or more participants should do to accomplish a specific business goal. According to Gartner [5] business process analysis tools are primarily intended for use by business end users looking to document, analyze and streamline complex processes, thereby improving productivity, increasing quality, and becoming more agile and effective. Classic business process analysis is oriented on analyzing and optimizing business processes for better productivity by saving time, costs or creating a more desirable product for customers.

Due to the increased need of agility competency-based management is crucial activity of contemporary business organizations. In this situation information technology support is the core element of the processes such as recruiting the most appropriate candidates, effective planning of employee development programs and project management. In many cases the information about competencies are exchanged between collaborating organizations.

The IT tools for supporting process modelling should therefore provide possibility to view the business process from the perspective of competencies required to perform particular tasks. Provision of information describing needed competencies of individuals involved in the process can help not only in workforce planning for the particular process but also in other management tasks such as expert finding, personalization of career paths and staff trainings. 
The area of enhancing business process models by competency information requires resolving two basic issues. Unfortunately none of the current business process modeling languages support the characterization of the business process in terms of competencies. Therefore the first issue is to find appropriate notation to include competency data in process models. The second challenge is to design a formal representation that would be enough expressive to provide the detailed view of the process from the competency perspective.

In recent years semantic models in form of ontology are increasingly popular way of formalizing, encoding and integrating knowledge from various sources to support business processes. In the domain of competency management semantic models can provide common definitions that can facilitate information exchange within an enterprise and throughout an industry. Another advantage of semantics is the possibility of automatic reasoning on the basis of semantic model and available information. This feature can be of great value while collecting data on competencies from many different resources such as internet portals with job offers, CVs of job applicants and databases of other organizations. Ultimately semantic models can help HR managers to compare and evaluate employees' knowledge and skills which is useful while developing project staffing plans or employees' professional trainings.

The aim of this paper is to show how the ontology describing competencies can be linked with business process models to support process-oriented, dynamic competency management in a company.

There are many frameworks describing competencies or useful to define them, which can be potentially useful in different domains. This frameworks are briefly described in section 2 . With this aim in mind the possibility of extending BPMN notation was presented in section 3. Ontological representation was proposed for annotating business process models and employee profiles. Further, a proposal of practical implementation of ontology-enhanced business process model was presented and illustrated by the example of software development (described in section 4).

\section{SEMANTIC MODELS FOR COMPETENCY MANAGEMENT}

According to Halper [6] a semantic model is a kind of knowledge model, which consists of a network of concepts and the relationships between those concepts. Concepts are a particular ideas or topics with which the user is concerned. The concepts and relationships together are often known as an ontology - the semantic model that describes knowledge. Competence models are one of the abstract layers of information system. They describe features and behaviors of people in relations to performed professional activities. Semantic models allow for systemizing the area of competency management by unifying concepts, measures and information resources about competencies. Therefore the semantic competence models can be useful in many areas such as knowledge management, planning career paths, personalizing vocational trainings, project management, periodic evaluation, employees' development.

From the manager's point of view an adequate approximation of employees efficiency is necessary, which can be presented as comprehend view of the knowledge, skills and personality features with regard to already performed or potential tasks. In the context of IT support, the effective competency management requires first of all well-defined meaning and unified understanding of competencies in perspective or business processes, finding balance between a level of detail in competency definition and complexity of management processes and well organized technical background consisting of different systems and services for supporting human resources management, employee training and knowledge management.

Current activities in the area of modelling and standardization of competency management include a number of initiatives oriented on different applications, namely:

- IMS-RDCEO - The Reusable Definition of Competency or Educational Objective (RDCEO) specification provides a means to create common understandings of competencies that appear as part of a learning or career plan, as learning pre-requisites, or as learning outcomes. The information model in this specification can be used to exchange these definitions between learning systems, human resource systems, learning content, competency or skills repositories, and other relevant systems. RDCEO provides unique references to descriptions of competencies or objectives for inclusion in other information models [7].

- HR-XML is a library of XML schemas developed by the HR-XML Consortium, Inc. to support a variety of business processes related to human resources management. The competencies schema which is a part of HR-XML allows for capturing of information about evidence used to substantiate a competency together with ratings and weights that can be used to rank, compare, and evaluate the sufficiency or desirability of a competency [8].

- InLOC [9] provides ways of representing intended learning outcomes, including knowledge, skills and competencies, so that the related information may be communicated between and used by ICT tools and services of all kinds, interoperably.

- O*NET [10] - is a database of all occupations in the US economy. It provides taxonomy of competencies and their elements and such as knowledge, skills, abilities and many other. The data was collected from companies operating in United States. The O*NET database can also serve as statistical tool to examine labor market in USA because it contains results of measurement of competency levels.

- E-CF - European e-Competence Framework - provides a reference of 40 competencies as applied at the Information and Communication Technology (ICT) workplace, using a common language for competencies, skills, knowledge and proficiency levels that can be understood across Europe [11]. 
Codification of competencies is the area predestinated to make use of ontologies. Competencies can be organized in a hierarchical, or a tree-like manner. Each competency can have any number of sub-competencies, which themselves can have sub-competencies. Creating a taxonomy is the first step to codification of organizational competencies. Then the semantic model can be formally defined and presented as ontology.

The ontologies of competencies can be employed in information systems supporting decision taking in domain of human resources, manufacturing and other related domains. Ontologies enhance the capabilities of applications in terms of searching for people with similar competencies regarding domain and level of knowledge and skills.

\section{EXTENDING BPMN}

In the business process management area, the Business Process Modeling Notation (BPMN) is the de-facto standard approved by ISO/OSI [12] which allows for multi-view and high-level description of business processes. BPMN provides means to describe collaboration, choreography and conversation aspects of business processes. However it does not offer standard support for the characterization of the business process in terms of many other specific aspects. These aspects are often related to the area in which the process is executed, some formal regulations and standards that the process must comply with.

There are many attempts described in literature aiming at enhancing modelling notations by additional information, which would help to understand better the domain or offer the specific views of the process. For example A. Rodríguez et al. [13] propose an extension for including data quality requirements in process models. P. Bocciarelli and A. D'Ambrogio describe a BPMN extension for modeling nonfunctional properties of business processes [14]. The extension of BPMN facilitating security risk management was proposed by O. Altuhhova at al. [15]. Few works focus on the methodology of extending BPMN by user-defined elements [16], so it can be interpreted as a lack of maturity in this area.

BPMN2.0 offers extensibility mechanism for enhancing standard BPMN notation with user-defined attributes and elements. This extensibility feature allows for addition of new types of artifacts. Modeling tools may include features to hide, or show these Artifacts. However the operations of adding the artifacts, hiding or showing them do not influence the sequence flow of the BPMN model. This is to ensure that BPMN diagrams always have a consistent structure and behavior [17].

The BPMN2.0 extension element consists essentially of four different classes which are [18 p.179]:

- Extension ExtensionDefinition defines additional attributes,

- Extension AttributeDefinition, presents the list of attributes that can be attached to any BPMN element,

- Extension AttributeValue contains attribute value.
The extension element of BPMN imports the definition and attributes with their values do the business process model. Adding new concepts to the model provides possibility to analyze it in different perspectives. From the point of view of competency management, BPMN models can be enhanced by artefacts representing knowledge and skills necessary to run the process. Such an extension would allow for establishing and populating competence requirements across the organization, its business partners and job candidates. BPMN models with references to the descriptions of the required competencies create yet another perspective for analyzing the process performance regarding human factor. Moreover having a unified model for description of competencies allows for addressing them on the stage of process design and further adjusting the process according to the current abilities of human resources.

In the next section a case study of integrating process model and a semantic model of competencies in form of ontology is presented on the basis of a process of software configuration management.

\section{INTEGRATING COMPETENCIES INTO PROCESS MODELS}

\section{A. Business process model with competency annotations}

This section describes a proposition of solution which integrates process models with competency ontology. The issue is presented on basis of software configuration management (SCM) process. SCM is one of the processes being integral part of software engineering projects carried out by software companies. The process of software configuration management consists of identifying and defining the configuration items, controlling the release and change of these items throughout the system lifecycle, recording and reporting the status of configuration items and change requests, and verifying the completeness and correctness of configuration items. It is a knowledgeintensive process that involves cooperation of many participants such as, managers, analysts, developers, testers and end-users.

The goal the SCM process is to successfully deliver a software product to a customer or market in accordance with customer's requirements and software company's business plan [19]. The decisions taken during this process by project managers are usually taken under the pressure of time and require skills from the areas such as: software design, construction, testing, sustainment, quality, security, safety, measurement and human-computer interaction.

The performance of SCM process is essential for software company because it directly impacts the customer satisfaction. Therefore decisions taken during the SCM process should regard both the customer's needs and the business case perspective. Therefore knowledge of related disciplines is very important as well as cognitive skills and behavioral attributes of the team members. The BPMN diagram of software configuration management process enhanced by competence artifacts is illustrated on fig. 1 . 
The presented business process model is annotated by the information on needed competencies. The annotations are added as an additional artefacts connected to the process tasks with dotted line. To make the diagram more readable added elements contain symbols (for example: A1, B2, C2) which reference to the Software Competence Ontology SCO (which is described later in this section). The symbols are displayed in form of hyperlinks so it is possible at any time to look up the detailed descriptions of knowledge and skills needed on each stage of the process.

In an example scenario a project manager wants to find the right people for preparing software and hardware configuration report which is one of the tasks in software configuration management process (fig.1). The presented business process model is annotated by the information on needed competencies. The annotations are added as an additional artefacts connected to the process tasks with dotted line. To make the diagram more readable added elements contain symbols (for example: A1, B2, C2) which reference to the Software Competence Ontology - SCO (which is described later in this section). The symbols are displayed in form of hyperlinks so it is possible at any time to look up the detailed descriptions of knowledge and skills needed on each stage of the process.

In an example scenario a project manager wants to find the right people for preparing software and hardware configuration report which is one of the tasks in software configuration management process (fig.1).

The manager formulates a query to find persons who have competency denoted in the process model as: B3(S5), which is described in SCO as follows:

- B - area "Build" - consists of competencies needed for building software.

- B3 - Competence no.3: "Constructs and executes systematic test procedures for ICT systems or customer usability requirements to establish compliance with design specifications. Ensures that new or revised components or systems perform to expectation. Ensures meeting of internal, external, national and international standards; including health and safety, usability, performance, reliability or compatibility. Produces documents and reports to evidence certification requirements."

- S5 - Skill no.5 of reporting and documenting tests and results.

The required level of competence are declared in the ontology using scale $1-5$, where 5 means the most advanced knowledge and skills. Meanings of particular levels are also explained in ontology. The classes and relations of the Software Competence Ontology are described in more detail in section 4.3.

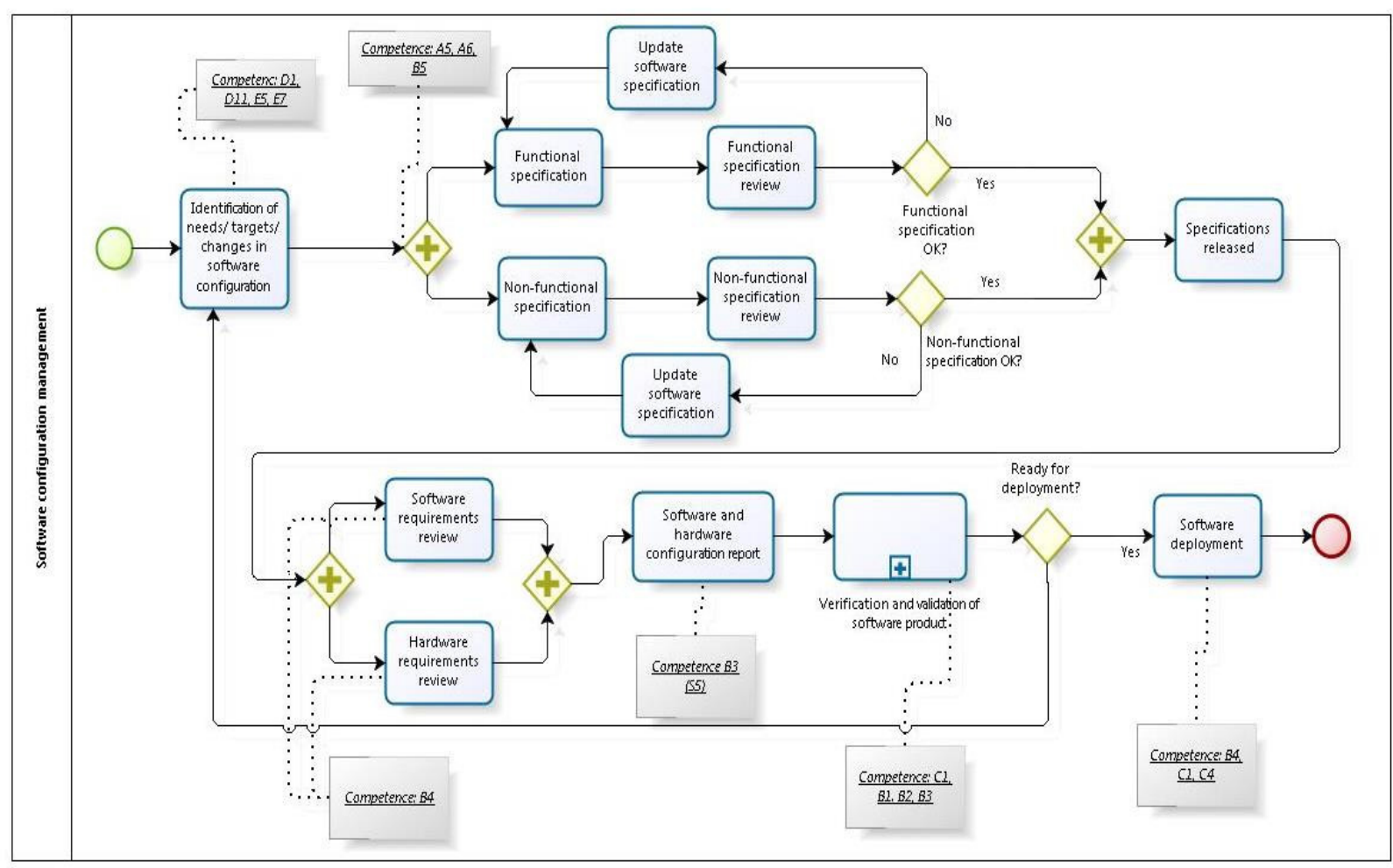

Fig. 1 BPMN diagram of software configuration management process with competencies annotations

Source: Own elaboration 


\section{B. General framework of the proposed solution}

The solution of integrating previously presented process with Software Competence Ontology is aimed first of all to facilitate finding the right person to perform a task in the process. Moreover the Software Competence Ontology can act as "common language" to describe the details of employees' profiles, annotating the CVs of job seekers, creating job postings and building a database of existing or potential business partners.

A general scheme of the platform supporting competency management is presented on fig.2. The project manager or HR manager while analyzing business process from the perspective of the competencies can formulate a query containing all the needed competencies and receive the list of potential contractors able to perform particular tasks.

The contractor can be an employee, a job seeker or a business partner who has knowledge and skills fully or partially consistent with the defined requirements. If there is no single person among the employees having all the required knowledge and skills for the given task, a team can be formulated consisting of the suggested individuals.

There are many possible data sources to use. The internal resources contain employees' profiles and CV of job candidates annotated with ontology concepts and references to knowledge and skills elements specified as the instances in the ontology. The external data sources may include information extracted from job hunting websites and databases shared by other organizations. If there are no people with proper competencies among the employees the database of job candidates or external databases exposed by business partners or job hunting portals can be searched through.

\section{Ontology of competencies}

As a reference for formalizing and codifying employees' competencies the European e-Competence Framework (E e$\mathrm{CF}$ ) was used. The choice was governed by many features of the $\mathrm{E}$ e-CF, which make it suitable for applying it in software development domain. The E e-CF is not based on job profiles but rather on competencies. This approach is more flexible and suitable for project-oriented companies (which is common in software industry) characterized by dynamic nature of the work environment, where employees are often from different departments and have different job titles. E e-CF provides general and comprehensive specification of e-Competencies described in a multidimensional structure which consists of:

- 5 competence areas - the E e-CF distinguishes between five competence areas derived from the general framework of ICT business process consisting in five phases: (A) plan, (B) build, (C) run, (D) enable, (E) manage,

- 40 competencies,

- 5 proficiency levels, where 1 denotes the weakest knowledge or skills,

- knowledge and skills examples.

All the dimensions can be adapted and customized into different contexts from ICT business. One drawback of the $\mathrm{E}$ e-CF is the lack of level specification for detailed knowledge and skills elements. There is only desired level

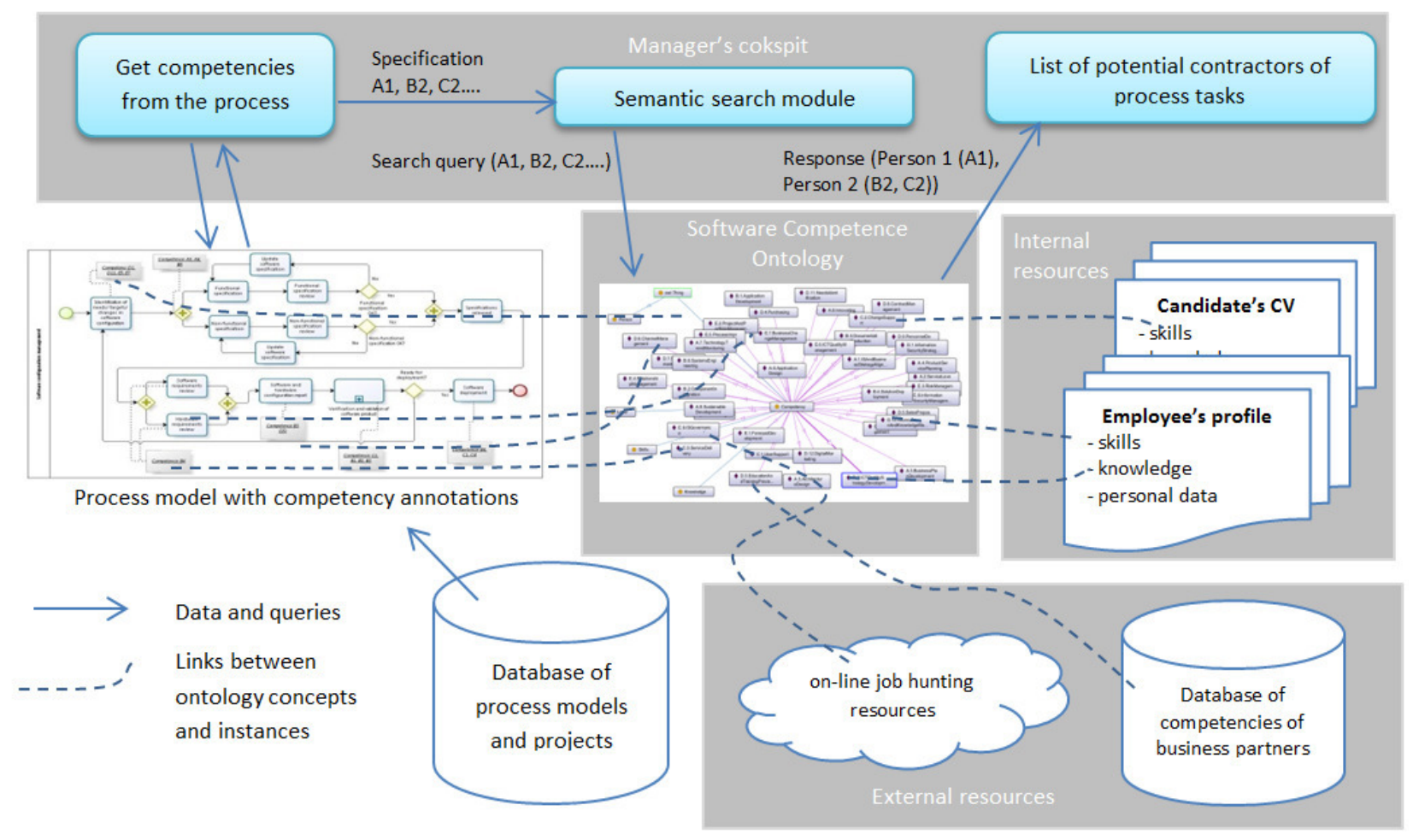

Fig. 2 General scheme of competency management framework Source: Own elaboration 
assigned to competencies. For example, the competence "A.1. IS and Business Strategy Alignment" has desired proficiency level 4 or 5 (in the $1-5$ scale). Therefore to compare the evidenced skills and knowledge of a person with desired level of competency specified in the ontology it is necessary to make assumptions about the desired levels of knowledge and skills elements.

In the prototype solution described here, the assumption was made that the desired levels of skills and knowledge are inherited from competency class. Therefore if the A1 Competence has desired level 4 or 5 , we assume that all the skills and knowledge elements also have the same desired levels (higher than 4).

The classes and relations defined in Software Competence Ontology are presented on fig. 3 .

The proposed definition of classes, properties and relations allows for semantic searching and reasoning. The following example queries can be posed:

- find persons who have evidenced level of competencies at least 3 in the area B (Build),

- find a person who can substitute with manager $\mathrm{X}$ in the project $\mathrm{Y}$.

The first example is simple and could be attained by a single query to the database. In the second case, if the requirements for project $\mathrm{Y}$ are defined according to the areas and levels specified in the ontology, the aim is to find a person who at least fulfills these requirements (the levels of competencies of the person are equal or higher than requirements). Another approach is to find a person who is most similar to Manager $\mathrm{X}$ regarding values of her competencies. Similarity can be calculated in many ways e.g. applying selected distance measure and computing distance between levels of competence of each pair of the persons.

Because the competency values can be represented as a vector, cosine similarity measure can be used. The cosine similarity for two vectors A and B is calculated as follows:

$$
\text { similarity }=\cos (\theta)=\frac{A \cdot B}{\|A\| \cdot\|B\|}=\frac{\sum_{i=1}^{n} A_{i} B_{i}}{\sqrt{\sum_{i=1}^{n} A_{i}^{2} \sqrt{\sum_{i=1}^{n} B_{i}^{2}}}}
$$

Where:

A - the vector representing values of competencies of manager $\mathrm{X}$

$\mathrm{B}$ - the vector representing values of competencies of other employee

Results of example calculation are presented in Tab.1

The cosine similarity factor in the above example shows that the most appropriate candidate to substitute Manager X is Employee 3.

The ontology of competencies also can be helpful if there is a need to analyze unstructured information such as CVs of candidates or new employees. In such a case semantic similarity measures can be used. The process of measuring semantic similarity is iterative and can be as follows:

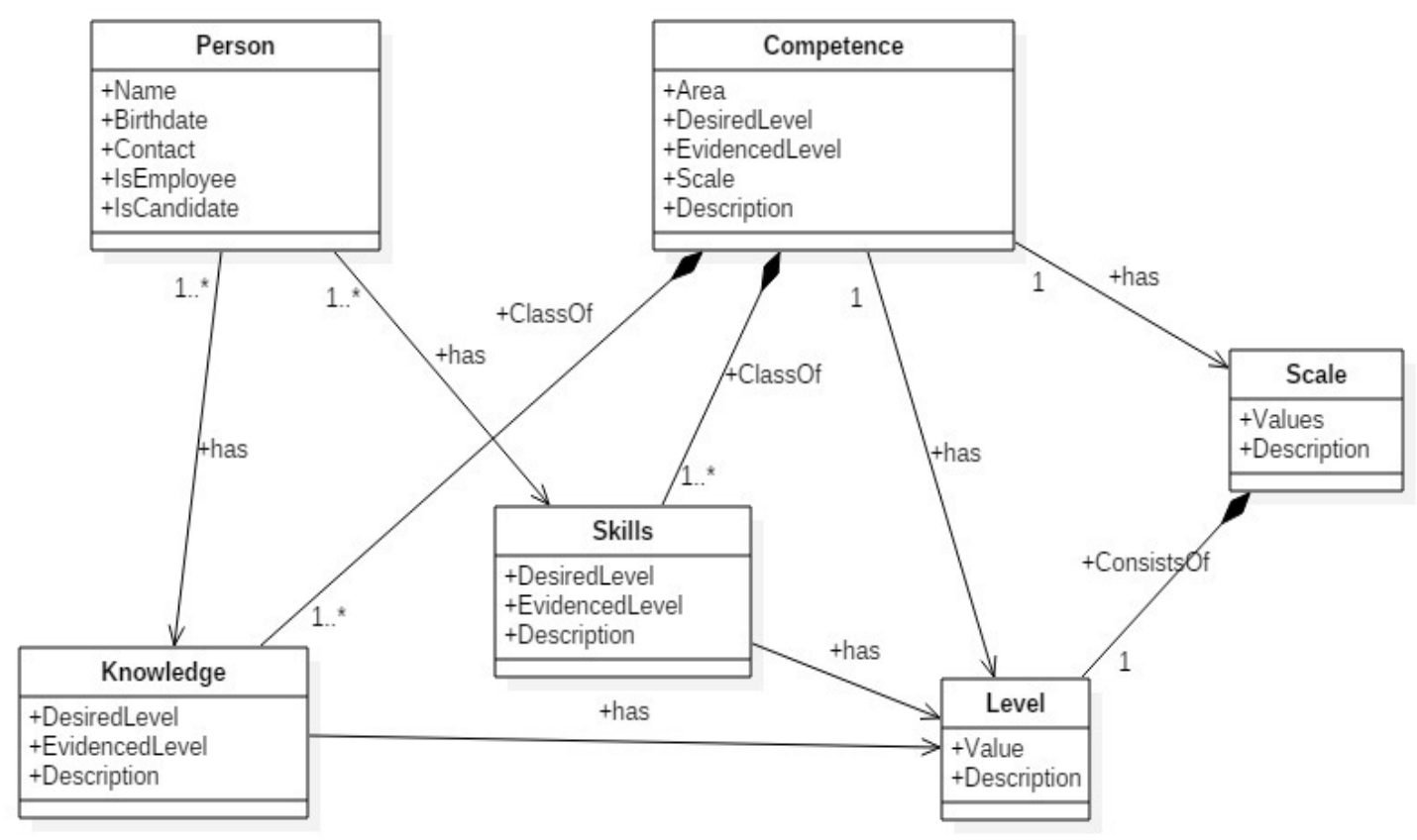

Fig. 3 Classes and relations in IT Competence Ontology

Source: Own elaboration 
TABLE I.

FINDING SIMILARITIES BETWEEN COMPETENCIES OF MANAGER X AND OTHER EMPLOYEES

\begin{tabular}{l|r|r|r|r|r|r|r|}
\hline $\begin{array}{c}\text { Competencies } \\
\text { needed in project } \\
\text { Y }\end{array}$ & $\begin{array}{c}\text { C.2. } \\
\text { Change } \\
\text { Support }\end{array}$ & $\begin{array}{c}\text { C.3. } \\
\text { Service } \\
\text { Delivery }\end{array}$ & $\begin{array}{c}\text { D.9. } \\
\text { Personnel } \\
\text { Development }\end{array}$ & $\begin{array}{c}\text { D.10. } \\
\text { Information } \\
\text { and Knowledge } \\
\text { Management }\end{array}$ & $\begin{array}{c}\text { E.8. } \\
\text { Information } \\
\text { Security } \\
\text { Management }\end{array}$ & $\begin{array}{c}\text { D.1. } \\
\text { Information } \\
\text { Security } \\
\text { Strategy } \\
\text { Development }\end{array}$ & $\begin{array}{c}\text { Cosine } \\
\text { similarity }\end{array}$ \\
\hline Manager X & $\mathbf{4}$ & $\mathbf{3}$ & $\mathbf{5}$ & $\mathbf{5}$ & $\mathbf{4}$ & $\mathbf{3}$ & - \\
\hline Employee 1 & 3 & 2 & 5 & 4 & 3 & 2 & 0,9895725 \\
\hline Employee 2 & 4 & 3 & 2 & 4 & 2 & 2 & 0,94778789 \\
\hline Employee 3 & 4 & 2 & 5 & 5 & 4 & 3 & 0,995199 \\
\hline
\end{tabular}

Source: Own elaboration

1. First, the text of the CV is analyzed to find keywords that are present in the descriptions of ontology classes and properties.

2. The thesaurus is used to find similar words in CV to those that are present in ontology.

3. Each time the keyword is found it is noted as one point for the given area and property of ontology.
4. When no more keywords are found the system displays suggestions of the areas and competencies identified for the given person.

5. The user engagement is needed to evaluate the competencies of the candidate in the scale 1-5 in the areas suggested by the system.

Another method is to apply semantic analysis of the terms used in descriptions of the employees' competencies. The

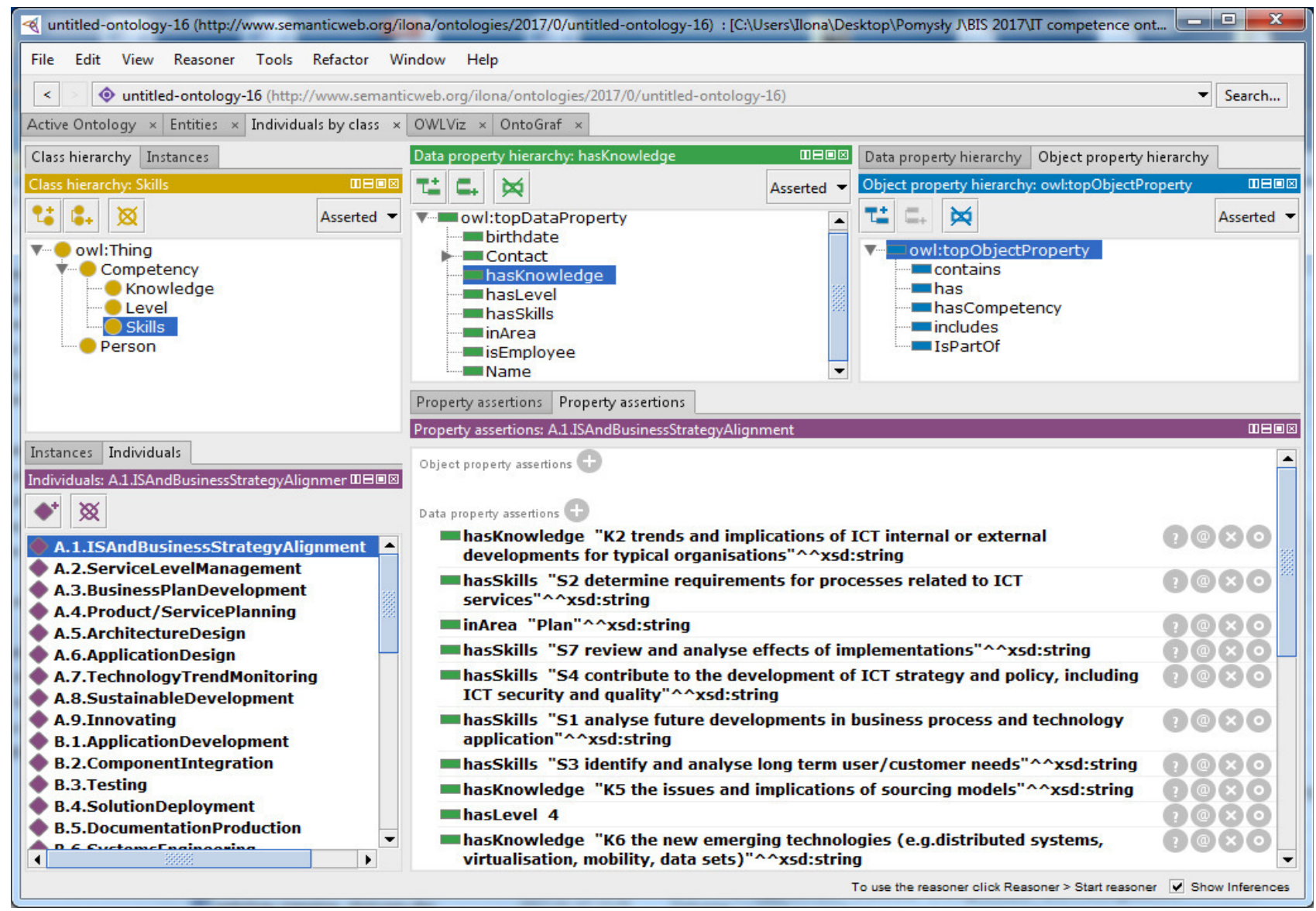

Fig. 4 Software Competence Ontology displayed in Protégé. Source: Own elaboration 
method is based on the use of a lexical database and semantic similarity algorithms. The lexical database WordNet [20] can be used as it is particularly well suited for similarity measures, since it organizes nouns and verbs into hierarchies of is-a relations [21].

The ontology of software competencies for the prototype of the system was coded using Protégé [22] platform (fig. 4). The instances of competencies on the base of $\mathrm{E}$ e-CF were imported from MS Excel file using Cellfie plugin of the Protégé platform.

The ontology classes are displayed in a left-top window, object and data properties in the middle and right top window. On the left bottom of the figure there are instances of competencies. The "IS and Business Strategy Alignment" competence is selected. On the right bottom window knowledge and skills elements for the selected competence are visible. Competencies are coded according to the 5 areas specified in the E e-CF framework and denoted with letters (A - Plan, B - Build, C - Run, D - Enable, E - Manage) and numbers.

\section{V.CONCLUSIONS AND FUTURE RESEARCH}

In this paper the concept of the platform for supporting process-oriented competency management has been proposed and illustrated by the example software configuration management process. The performance of SCM process depends upon proficiency of people involved in the process execution, therefore it is necessary to know the ideal bundle of competencies that the project team should evidence. Having a database of employees and job applicants profiles with specified skills, knowledge and employment history, allows to match the competencies specified in the process model against evidenced levels of proficiency.

The dynamic approach to manage competencies on the base of business process flow can be valuable for process based and virtual organizations where the environment is dynamic and frequent changes are needed to preserve the company's competitiveness and agility, this is often the case of software companies. IT labor market is, constantly changing due to continuous advancements in technology and innovative products. New competencies show up and competencies that are already in existence, change their contents [23].

The Software Competence Ontology was developed in Protégé on the basis of European e-Competence Framework. The proposed Ontology will be further developed, especially by additional dictionaries and domain ontologies with the aim to improve semantic search algorithms. By the use of dictionaries of synonyms it would be possible to enhance semantic search with the possibility of finding similar or the same competencies described with different terms. It is especially useful while dealing with external resources such as job hunters websites or databases of competencies that could be exposed by other business entities.
Competency management, can be seen as one of the most important drivers of business processes performance improvement, therefore there is a growing need for systematic approaches and IT support in this area.

\section{ACKNOWLEDGMENT}

This work was conducted using the Protégé resource, which is supported by grant GM10331601 from the National Institute of General Medical Sciences of the United States National Institutes of Health

\section{REFERENCES}

[1] M. Bratnicki: Kompetencje przedsiębiorstwa. Od określenia kompetencji do zbudowania strategii. Agencja Wydawnicza Placet, Warszawa, 2000

[2] P. Selznick: Leadership in administration. New York: Harper, 1957.

[3] C.K. Prahalad and G. Hamel: "The core competence of the corporation," Harvard Business Review, pp. 79-91, May-June 1990

[4] K. Leyking and R. Angeli: "Model-based, Competency-Oriented Business Process Analysis," Enterprise Modelling and Information Systems Architecture Journal, 4(1), pp. 14-25, 2009

[5] http://www.gartner.com/it-glossary/bpa-business-process-analysistools/

[6] F. Halper: What's a semantic data model and why should we care? (2007) https://datamakesworld.com/2007/11/29/whats-a-semanticmodel-and-why-should-we-care/ access: May 2017.

[7] IMS Global Learning Consortium: IMS Reusable Definition of Competency or Educational Objective Specification https://www.imsglobal.org/competencies/ access: May 2017.

[8] HR-XML Consortium, Competencies (Measurable Characteristics) Recommendation,

2004 http://www.ec.tuwien.ac.at/ dorn/Courses/KM/Resources/hrxml/HRXML-2 3/CPO/Competencies.html access: May 2017.

[9] InLOC $^{-}$(Integrating Learning Outcomes and Competences) http://www.cetis.org.uk/inloc/Home access: May 2017.

[10] https://www.onetonline.org/ access: May 2017

[11] European e-Competence Framework: A common European framework for ICT Professionals in all industry sectors, 2016 http://www.ecompetences.eu/ access: May 2017.

[12] ISO 10303-203:1994 Information technology - object management group business process model and notation, 1994.

[13] A Rodriguez, A. Caro, C. Cappiello, and I. Caballero: "A BPMN extension for including data quality requirements in business process modeling. In: Mendling, J., Weidlich, M. (eds.) BPMN 2012. LNBIP, vol. 125, pp. 116-125. Springer, Heidelberg (2012)

[14] Bocciarelli, P., D'Ambrogio, A.: A BPMN extension for modeling non functional properties of business processes," in: Proc. of the 2011 Symposium on Theory of Modeling \& Simulation: DEVS Integrative M \& S Symposium, TMS-DEVS 2011, Society for Computer Simulation International, San Diego, 2011, pp. 160-168.

[15] O. Alluhhova, R. Matulevicius, N. Ahmed: "An Extension of Business Process Model and Notation for Security Risk Management," International Journal of Information System Modelling and Design vol.4(4) pp. 93-113, 2013

[16] L. J. R. Stroppi, O. Chiotti, and P.D. Villarreal: "Extending BPMN 2.0: Method and tool support," in: R. Dijkman, J. Hofstetter and J. Koehler, (eds.): BPMN 2011. LNBIP, vol. 95, Springer, Heidelberg, 2011, pp. 59-73.

[17] S. White and D. Miers: "BPMN Modeling and Reference Guide: Understanding and Using BPMN," Future Strategies Inc., Lighthouse Point, FL, USA, 2008.

[18] P. Lorenz, J. Cardoso, L. Maciaszek, and M. van Sinderen (eds.): "Software Technologies - 10th International Joint Conference, ICSOFT 2015, Colmar, France, July 20-22, 2015, Revised Selected Papers," in Communications in Computer and Information Science: Vol. 586. pp. 210-227 Springer, 2015.

[19] J. Farah: "Defining a Software Configuration Management Process to Improve Quality", 2012 https://www.cmcrossroads.com/article/nextgeneration-process-and-quality-0 access: May 2017. 
[20] Princeton University "About WordNet." WordNet. Princeton University. 2010. http://wordnet.princeton.edu access: May 2017

[21] T. Pedersen, S. Patwardhan, and J. Michelizzi: WordNet: Similarity Measuring the Relatedness of Concepts. In: AAAI 2004. San Jose, CA. pp. 1024-1025, 2004.
[22] http://protege.stanford.edu

[23] P. Rózewski, B. Małachowski, and P. Danczura: Concept of competence management system for Polish National Qualification Framework in the Computer Science area. In: Ganzha. M.. Maciaszek. L.A.. Paprzycki. M. (eds.) FedCSIS. pp. 759-765, 2013. 